\title{
Fostering Undergraduate Research Experiences In Management Information Systems Through The "Research Group" Framework
}

Ken Bartkus, Utah State University, USA Robert Mills, Utah State University, USA David Olsen, Utah State University, USA

\begin{abstract}
The purpose of this paper is to propose an innovative approach to engaged learning. Founded on the principles of a scholarly think-tank and administered along the lines of a consulting organization, the proposed 'Research Group' framework is designed to facilitate effective and efficient undergraduate research experiences in Management Information Systems and other business areas. In doing so, the program better prepares students for success in graduate school and their chosen careers. In this paper, we introduce the research group framework and describe its four fundamental elements. Examples of are then presented to illustrate both scholar-based and organization-based research experiences. We conclude with a discussion on the challenges of developing a formal undergraduate research program.
\end{abstract}

\section{INTRODUCTION}

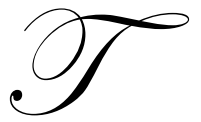

here is overwhelming consensus that undergraduate research experiences (URE) provide meaningful benefits to students, faculty, universities, and society. Elgren and Hensel (2006) note that "Inviting students to invest intellectually in a project gives them the opportunity to help shape its direction, exert some of their own creativity, and experience the joy of intellectual 'ownership' of the products resulting from the effort". Schneider (2004) maintains that undergraduate research programs can "result in more successful and competitive alumni, serve as a selling point for recruiting freshman, provide positive publicity, lead to greater overall productivity, and impart a more mature learning atmosphere."

Lopatto (2006) suggests that undergraduate research contributes to the personal development of students including growth in self-confidence, increased tolerance for obstacles, interest in the discipline, and a sense of accomplishment. Gates et al. (1999) maintain that undergraduate research helps better prepare undergraduate students for graduate research requirements. Finally, Ulmbach and Porter (2002) found that faculty contact with students and a research emphasis had a "significant impact on satisfaction with education in the major and the perceived impact that college had on skill development".

Given this background, it should not be surprising to learn that participation in undergraduate research experiences throughout the United States is high and that there exists a multitude of published research on programs.

With regard to participation, the National Council on Undergraduate Research sponsors an annual conferences where undergraduate researchers have an opportunity to present. It appears, however, that MIS participation is relatively low. Specifically, of the approximately 2,000 presentations made at the 2008 conference, business projects accounted for about 5 percent and, of these, MIS represented about 3 percent. This equates to less than 1 percent of the total projects presented at NCUR. Since NCUR is the major national conference for disseminating undergraduate research, the relative lack of participation in the area of MIS suggests that we are not optimizing our potential. 
With regard to published research, a review of the literature failed to identify much development in the area of MIS although articles have been published in other business areas such as accounting and finance (Fogarty \& Mayo 1999; Jalbert 2008), marketing (Peltier, Schibrowsky, Kleimenhagen, 1995), and operations (Stößlein \& Kanet 2008).

Only article could be found that explicitly focused on management information systems. Specifically, Knox, DePasquale, and Pulimood (2006) proposed a model for Undergraduate Research Experiences in "emerging technologies". While the model represents a step in the right direction, it is limited by the fact that it was designed for a summer program and focused on a relatively narrow, albeit important, topic within MIS (i.e., information security).

Given the importance placed on undergraduate research experiences combined with the relative lack of formal involvement by management information systems programs, additional research is needed to provide a solution.

How can MIS programs effectively and efficiently implement an undergraduate research program? The purpose of this paper is to propose a framework used by a major land-grant university to promote undergraduate research and demonstrate how it can be applied to an MIS program of study.

\section{FRAMEWORK: THE RESEARCH GROUP ${ }^{\mathrm{TM}}$}

The Research Group ${ }^{\mathrm{TM}}$ was formally established in 2007 and in 2008 received national recognition from the American Association of University Administrators as an outstanding example of administrative leadership. Based on the principles of a scholarly think tank and administered along the lines of a consulting organization, it can be shown that the framework has important implications for MIS programs. We begin with a review of four fundamental elements of the program: (1) the mission, (2) the administrative structure, (3) the guiding principles, and (4) the implementation challenges. We conclude with two case examples that serve to demonstrate how the program has provided value to students, to faculty and the university, and to society.

\section{The Mission}

The Research Group ${ }^{\mathrm{TM}}$ is a nationally recognized consortium of university scholars, corporate leaders, and qualified undergraduate students dedicated to high quality research experiences that contribute to the knowledge base of the business discipline and to the profession of business. Its primary objective is to provide students the opportunity to participate in a scholarly think tank and, in doing so, develop core competencies in the analytical methods used to solve meaningful business and public policy issues. Students engage in research sponsored through The Research Group ${ }^{\mathrm{TM}}$ become better prepared for success in graduate school and their chosen careers. The guiding motto of The Research Group ${ }^{\mathrm{TM}}$ is Research that Matters.

\section{The Administrative Structure}

To support the mission, an administrative structure was developed to reflect a real-world business organization. In doing so, the structure sought to bridge the gap between purely educational and purely work environments. This led to the following:

1. Director: responsible for coordinating the research activities of the group and to serve as a liaison to the business community and college/university administration.

2. Managing Partners: business scholars who are responsible for coordinating individual projects in their respective business disciplines, and serve on the advisory board for the program.

3. Faculty Partners: business scholars who participate in student/faculty research collaborations. Faculty Partnerships are open to all faculty at the university.

4. Corporate Partners: recognized industry leaders who provide advisory counsel to the group and serve as liaisons to the business community.

5. Associates and Senior Associates: students engaged in collaborative research with faculty. 
An important benefit of the structure is that it allows recognition of faculty and student contributions that might otherwise be overlooked in less formal models. For example, students can list their participation on their resumes as work experience (e.g., students can participate in the program as an internship experience). Similarly, faculty can list mentoring as service, teaching, and research activity. Finally, the structure helps communicate the benefits of the program to relevant stakeholders (such as students, future employers, graduate schools, the state legislature, and boards of regents and trustees, among others).

\section{Guiding Principles}

Goals and objectives were then developed to serve as guiding principles:

1. Undergraduate Research Experiences should be meaningful.

1.1. Meaningful research experiences promote an understanding of the scientific method and its application to business-related issues. The scientific method is at the core of business and an understanding of its application to solving business questions is essential.

1.2. Meaningful experiences meet the career and academic interests of students. They are not simply another hurdle in the education experience.

1.3. Undergraduate research experiences are time efficient. Most projects can be completed in one academic year or less.

1.4. Meaningful research experiences involve students as collaborators rather than merely assistants. The real world will treat graduates as part of a team and not as students. The research group framework helps facilitate this transition.

2. Undergraduate research experiences prepare students for graduate study.

2.1 The program prepares students for graduate study, where an understanding of the principles of scientific inquiry are essential.

3. Undergraduate research experience involves presentations.

3.1 Presentation of research allows students to gain valuable experience that will be useful in graduate school and/or their chosen careers.

3.2 Students are encouraged to present at national, state, and regional venues specifically dedicated to for undergraduate research (e.g., National Conference on Undergraduate Research) as well as professional conferences.

4. Undergraduate research experiences include participation in Research Forums/Symposiums at the University.

4.1 Research Forums/Symposiums within the school of business allow students to share ideas and develop an esprit de corps.

5. Undergraduate research programs participate in scholarly organizations dedicated to undergraduate research.

5.1 The National Council on Undergraduate Research is the major organization dedicated to student achievement in research. It is administered through the contributions of interested faculty. Many states and regions are also developing their own organizations to promotion undergraduate research.

5.2 The Council on Undergraduate Research is the major organization dedicated to faculty development in the area of undergraduate research. Faculty play an important role in the direction of the organization.

\section{Implementation Challenges}

Any program development will inevitably face implementation challenges. The Research Group ${ }^{\mathrm{TM}}$ was no different. Among the major challenges were: (1) recruiting qualified students, (2) securing faculty support, (3) fostering administrative support, and (4) identifying meaningful projects. 


\section{Recruiting Qualified Students}

Our experience has been that qualification for the program should start with academic standing, which usually means grade point average. Although not a perfect measure, we reasoned that the program needed to be selective given limited faculty resources. Similarly, we considered setting limits based on class level (e.g., junior and above), but ultimately felt that this was overly restrictive.

In this regard, it was argued that we could have a stronger influence if we attracted the most qualified students early in their academic careers. Two of our most productive associates began their involvement with The Research Group ${ }^{\mathrm{TM}}$ as first-year students.

\section{Securing Faculty Support}

Each faculty member becomes a faculty partner in The Research Group. The recognition aids in each component of the performance evaluation portfolio; teaching, research, and service. With regard to teaching, participation in the program provides bona fide evidence of innovation in teaching through student/faculty research collaborations. Our school also recognizes an undergraduate research mentor of the year which provides additional incentives to participate in the program. The mentor is also recognized at the university level during an awards ceremony.

In the area of research, many of our collaborations have resulted in publication. Related to this, we have found that the central administration of our university responds favorably to our students publishing with faculty. We also argue that participation in The Research Group provides evidence of service to the school since the group is a consortium that requires member support.

Finally, we have argued that undergraduate research mentoring should be recognized in the promotion and tenure process. First, we sought to include a reference to undergraduate research mentoring in the role statements of tenure-track faculty. In addition, we have recommended that it be included in the formal university guidelines for tenure and promotion.

In each of these ways, involvement in The Research Group is designed to provide tangible benefits to the faculty member's performance package.

\section{Fostering Administrative Support}

One of the most straightforward means of securing administrative support is to request to have someone appointed to the position of Director of Undergraduate Research Programs. Two things naturally follow from this. First, it opens a direct line of communication to administration whereby the accomplishments of faculty and students can be promoted.

Second, it provides a foundation for funding support. We have found that as the program developed and achieved more success, the administration was more willing to provide additional funding to support additions to the program.

\section{Identifying Meaningful Projects}

Identification of meaningful research is critical to the success of a program. One way to do this is to ask students to find a topic area on their own by reviewing the literature. Our experience with this approach is that it all too often leads to frustration for both the mentor and the student. The reason is that students typically do not have the requisite experience to identify meaningful and doable projects. As such, they may spend weeks or longer developing a proposal that is not acceptable. For example, to help overcome this challenge, we typically start the experience by having students participate in a project that has been at least partially conceptualized by the mentor. In doing so, the background work has been established which allows the mentoring process to be more effective and efficient. As students gain more experience, they are then able to develop projects on their own. 
The downside of this process is that faculty are sharing some of their own research with students. Thus, care should be taken in how project ideas are allocated. For example, it doesn't make sense to include a student on a project that requires significant theoretical understanding and/or sophisticated methods of analysis. Instead, smaller projects that require less preparation are typically more suitable.

In the final analysis, the issue is one of matching the rigor of the study with the capabilities of the students. As students gain experience, we have found that the level of rigor increases as well.

\section{EXEMPLARS OF MIS UNDERGRADUATE RESEARCH EXPERIENCES}

The Research Group at our university has been active in promoting undergraduate research experiences for MIS students. Two exemplars are presented in the following cases.

\section{Scholarly-based Research}

Scholarly-based research is a core component to the undergraduate research experience. An example of a successful undergraduate research was a project initiated by an undergraduate student who examined auction prices for high desirability items in the context of the electronic commerce (EC) consumer behavior model. The findings of his research supported the possibility that high desirability products attenuate the impact of a seller's rating on auctions prices. His research was presented at a respected MIS conference and has been submitted to a refereed journal. This student will enter his senior year this fall and has stated that his published research is giving him a substantial advantage as he applies to graduate programs and prestigious MIS consulting firms.

\section{Organization-based research}

Organization-based research is another core component to the undergraduate research experience. This approach follows the adult learning principle that adult learners learn best from hands-on, problem solving approaches to learning.

An example of a successful organization-based research includes a performance improvement class that works directly with a major professional basketball arena. Performance improvement solutions have been designed and developed for security, evacuation, operations, food services, ticket office, and guest services.

These projects have provided students with outstanding portfolio pieces which help them secure employment upon graduation. The students really appreciate the opportunity to work with a major organization. "I think that the [program] we developed is going to help me a lot as I get into the business world. I love assignments that allow you to practice what you're being taught. It makes me less nervous about being able to perform in my future job. I'll know what it takes to get it done" (Excerpt from a former student evaluation).

\section{CONCLUSIONS}

We have proposed the Research Group framework as a way to help systemize the process and thereby facilitate higher quality undergraduate research experiences for students. Our experience with the program has been encouraging. Our students have their research presented at undergraduate research venues as Research Day at the State Capital and the National Conference on Undergraduate Research and many have collaborated with faculty on research that has led to publications in scholarly journals and conference proceedings. Others have presented their research reports to major companies. We believe that much of this success is the result of using a systematic approach to undergraduate research experiences. Indeed, the research group framework has been formally recognized as an exemplary model by the American Association of University Administrators. To this end, we would like to broaden the framework by proposing the development of a consortium of MIS programs who could work together to promote greater synergies in undergraduate research. At a minimum, we hope that this essay serves to promote greater discussion and debate regarding the importance of undergraduate research. 


\section{REFERENCES AND RECOMMENDED READINGS}

1. $\quad$ Elgren T, Hensel N. (2006). "Undergraduate research experiences: Synergies between scholarship and teaching," Peer Review, (8), 409-414.

2. Fogarty, E. \& H. Mayo (1999). "Undergraduate research: the senior thesis in finance," Financial Services Review; 223-234.

3. Gates A, Teller P, Bernat, A, Delgado, N, \& Della-Piana C. (1999). "Expanding participation in undergraduate research using the affinity group model," Journal of Engineering Education, (88), 409-414.

4. Jalbert, T (2008). "Experiences in publishing peer-reviewed research with undergraduate accounting and finance students," Journal of Accounting Education, 26(3), 104-117.

5. Knox, D. L., DePasquale, P. J., \& Pulimood, S. M. (2006). A model for summer undergraduate research experiences in emerging technologies. ACM Special Interest Group on Computer Science Education, 38(1), 214-218.

6. $\quad$ Lopatto D. (2006). "Undergraduate research as a catalyst for liberal learning," Peer Review, (8), 22-25.

7. Peltier, J.W., J. Schibrowsky, \& A. Kleimenhagen (1995). "Student-Faculty Research Agencies: Marketing Education Integration Using an Entrepreneurial Education Experience," Journal of Marketing Education, 17(2), 59-70.

8. $\quad$ Schneider L.E. (2004). "Undergraduate research: Responsibility of a research university," Journal of Water Resource Planning and Management, 130, 89-92.

9. Stößlein, M. \& J. Kanet, (2008). "Developing Undergraduate Student Research Experiences in Operations Management," Decision Sciences Journal of Innovative Education, 6(2), 495-502.

10. Umbach P. \& Porter S. (2002). "How do academic departments impact student satisfaction? Understanding the contextual effects of departments," Research in Higher Education, 43, 209-234. 